\title{
Arteterapia: una experiencia de implementación remedial voluntaria en universitarios
}

\author{
Art Therapy: A Voluntary Remedial Implementation Experience in University \\ Students
}

\begin{abstract}
Arteterapia: uma experiência de implementação corretiva voluntária em estudantes universitários

Grace Marlene Rojas Borboa

Instituto Tecnológico de Sonora, México

grace.rojas@itson.edu.mx https://orcid.org/0000-0003-0319-0367

Luz Alicia Galván Parra

Instituto Tecnológico de Sonora, México

luz.galvan@itson.edu.mx https://orcid.org/0000-0002-7566-8035
\end{abstract}

\section{Resumen}

Se implementaron talleres de arteterapia a universitarios que determinaron estar pasando por estrés, lo cual estaba afectando sus resultados, con el objetivo de disminuir sus estresores y mejorar su rendimiento académico. Se utilizaron los métodos de Fux (2007) y Sheykholya (2013), después de ser adaptados para jóvenes. A partir de ello se realizó un estudio descriptivo y transversal; una escala Likert de observación elaborada para tal fin fue aplicada previo y al cierre de los talleres. Como parte de los resultados, se encontraron cambios significativos en su actitud al trabajo en grupos heterogéneos y en equipo, a su apreciación musical, al trabajo con contenido matérico y más aún a expresar sus emociones con aprecio por el grupo. Es importante seguir desarrollando estos talleres y favorecer a más estudiantes; además de realizar estudios correlacionales, causales y longitudinales que den base a la gestión de recursos para impactar a una mayor población. 


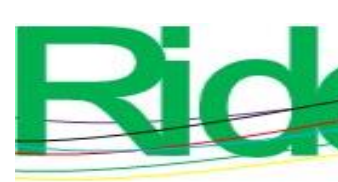
Revista Iberoamericana para la
Investigación y el Desarrollo Educativo
ISSN $2007-7467$

Palabras clave: artes, emociones, estrés, rendimiento académico, terapia.

\begin{abstract}
Art therapy workshops were implemented for university students who admitted to be going through university stress, which was affecting their results, in order to reduce their stressors and improve their academic performance. The methods of Fux (2007) and Sheykholya (2013) were used, adapting them for young people. Based on this, a descriptive, mixed and crosssectional study was carried out; a Likert scale of observation developed for this purpose was applied before and at the end of the workshops. As part of the results, significant changes were found in their attitude to work in heterogeneous groups and in teams, to their musical appreciation and with material content and even more to express their emotions with appreciation for the group. It is important to continue developing these workshops and favor more university students. It is also important to continue conducting correlational, causal and longitudinal studies that give basis to the management of resources to impact a larger population.
\end{abstract}

Keywords: art therapy, emotions, stress, academic performance.

\title{
Resumo
}

Foram realizadas oficinas de arteterapia para estudantes universitários que determinaram que estavam sofrendo estresse, o que estava afetando seus resultados, com o objetivo de reduzir seus estressores e melhorar seu desempenho acadêmico. Os métodos de Fux (2007) e Sheykholya (2013) foram utilizados, após serem adaptados para a juventude. A partir disso, foi realizado um estudo descritivo e transversal; Uma escala de observação Likert desenvolvida para esse fim foi aplicada antes e no encerramento das oficinas. Como parte dos resultados, foram encontradas mudanças significativas em sua atitude de trabalhar em grupos heterogêneos e em equipes, em sua apreciação musical, em trabalhar com conteúdo material e ainda mais em expressar suas emoções com apreciação pelo grupo. É importante continuar desenvolvendo esses workshops e favorecendo mais estudantes; além de realizar estudos correlacionais, causais e longitudinais que baseiam o gerenciamento de recursos para impactar uma população maior.

Palavras-chave: artes, emoções, estresse, desempenho acadêmico, terapia. 


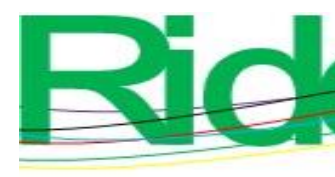

Fecha Recepción: Febrero 2020
Revista Iberoamericana para la

Investigación y el Desarrollo Educativo

ISSN $2007-7467$

Fecha Aceptación: Julio 2020

\section{Introducción}

Las universidades hoy en día buscan la formación integral del estudiante. Las áreas de atención a sus necesidades académicas, deportivas, culturales, emocionales, laborales y demás han crecido, lo cual les ha otorgado mayores oportunidades para ser exitosos profesional y personalmente. Así, es común observar que si un alumno requiere de asesorías de matemáticas existen tutores o monitores par; si necesita habilitarse en lo especializado de su profesión, va a prácticas en empresas a través de la vinculación; hace deporte curricular o extraclase; hay psicólogos dedicados a su atención individual o familiar; se le proporcionan eventos o festivales artísticos para su formación cultural, así como talleres y cursos de formación general.

Los jóvenes hacen uso de las artes para sentirse en paz, en armonía y con completa libertad de expresarse, o bien para proyectarse ante las diversas sensaciones positivas o negativas que viven o han experimentado. Son un escaparate. A través de las artes pueden dar rienda suelta a su imaginación, a su creatividad y a diversos sentimientos que normalmene se mantienen contenidos y que son producidos por experiencias y problemáticas de la vida diaria.

\section{Antecedentes}

En la actualidad son varias las preocupaciones de los universitarios: el simple hecho de estar cursando una carrera es motivo de presión personal, profesional y familiar. Por lo que una de las funciones primordiales de la escuela es promover el buen manejo y control de las emociones, y que con esta capacidad emocional puedan insertarse favorablemente en cualquier contexto.

Hay que tener en cuenta que el no hacer introspección de las reacciones puede incidir en la eficiencia terminal. Por ello, Páez y Castaño (2015) dicen que es importante el diseño de currículos pedagógicos que enfaticen en los aspectos cognitivo, emocional e interaccional, ya que estos se asocian con el rendimiento académico, el ajuste psicológico y el desempeño laboral. Además, otros estudios señalan que se deben crear nuevas alternativas de mejora mediante el uso de arteterapia como estrategia de incremento de motivación, para reducir la deserción escolar (Casaliglla, 2019). 


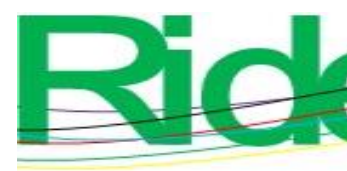

Revista Iberoamericana para la
Investigación y el Desarrollo Educativo
ISSN $2007-7467$

Las condiciones de salud de los estudiantes, mentales, físicas y emocionales, se ven afectadas desde que entran a la universidad, y continúan viéndose aún más afectadas a medida que crecen sus exigencias académicas y entran en juego variables como horarios, ritmo de trabajo, sueño, adquisición de habilidades, situaciones de competencia, éxitos, fracasos, alimentación, presiones de grupo o equipos y demás, sin dejar de lado las relaciones maestroalumno, las cuales también se reportan como generadoras de estrés. Tal es así que más de $70 \%$ de estudiantes con estrés académico llegan a padecer depresión. Por lo que, sin duda, se trata de un fenómeno importante que debe ser atendido en los centros de bienestar estudiantil de las universidades (Gutiérrez, Montoya, Toro, Briñon, Rosas y Salazar, 2010).

\section{Planteamiento del problema}

El Instituto Tecnológico de Sonora (ITSON), a través de sus programas educativos y área de Vinculación, lleva a la comunidad diversos proyectos de intervención o atención comunitaria para allegar algunos servicios que apoyen lo que la educación y otros organismos hacen en favor de la calidad de vida de esos habitantes en condiciones de vulnerabilidad. Los resultados obtenidos en la línea de educación artística con niños, adolescentes, mujeres y personas de la tercera edad han sido tan favorables que hizo pensar que sus problemas y diferentes estresores podrían ser parecidos a los que provocan bajos indicadores en los estudiantes universitarios. Por eso se platicó con los responsables de las áreas académicas y se decidió adaptar los programas e invitar a alumnos que, bajo su propia perspectiva, les fuera útil atender sus problemas académicos mediante actividades que mejoraran sus emociones.

Según Arturo Barraza (2011), el estrés académico es un proceso sistémico, de carácter adaptativo y esencialmente psicológico, que se presenta cuando el alumno se ve sometido, en contextos escolares, a una serie de demandas que, bajo la valoración del propio alumno, son consideradas estresores. Estos provocan un desequilibrio que se manifiesta en una serie de síntomas que obliga al alumno a realizar acciones de afrontamiento para restaurar el equilibrio sistémico (Barraza, 2011).

Toribio y Franco (2016) señalan que los principales estresores que han identificados en alumnos de licenciaturas en áreas de la salud son: los exámenes, la sobrecarga académica, el corto periodo de entrega de estas y la personalidad/carácter del profesor. 


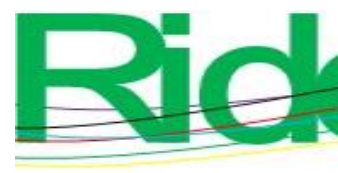

Revista Iberoamericana para la Investigación y el Desarrollo Educativo ISSN $2007-7467$

Así, dado los resultados que se han obtenido en comunidad y algunas certificaciones en arteterapia que han recibido alumnas y maestras de la licenciatura en Gestión y Desarrollo de las Artes, se buscó replicar estos talleres en alumnos de la universidad que cuenten con algún antecedente de problemas académicos o sean vulnerables por causas de estrés con la intención de que su participación les ayuda a mejorar su desempeño general. Lo anterior bajo la premisa de que existe correlación entre la vida universitaria y el estrés, y de que este puede disminuirse a través de las artes.

La pregunta detonante fue: ¿aplicar actividades de arteterapia en estudiantes con problemas de estrés ayudará en su rendimiento académico?

\section{Objetivo}

Implementar un taller de arteterapia en universitarios del sur de Sonora, México, para documentar los beneficios que los participantes obtienen al disminuir su estrés respecto a su rendimiento académico.

\section{Justificación teórica}

Aunque esta no es una investigación en el área de la salud mental, tampoco se trata de curar a la gente; más bien es darle a los estudiantes la oportunidad de cambiar, es otra forma de potenciar sus habilidades (Pereira, 18 de agosto de 2016). Arrieta, Díaz y González (2014) señalan que el aumento de las conductas depresivas y ansiosas en los alumnos se debe a que en el ambiente universitario están constantemente a prueba con el fin de desarrollar competencias, mediante exigencias académicas, responsabilidades, evaluaciones, trabajos, presión familiar y problemas económicos, sin dejar de tomar en cuenta el sexo, el alcohol, las enfermedades y los sucesos familiares.

Para Dalley (1987), la arteterapia se considera como el uso del arte en un contexto terapéutico, donde lo más importante es la persona y el proceso y el arte se utiliza como un medio de comunicación no verbal. Por otra parte, Gardner (2016) ha señalado que entre las diferentes inteligencias está la artística. También ha apuntado que varias de ellas están relacionadas y pueden, además, potenciarse a través de la que se demuestre es la de mayor fortaleza (Gardner, 2016). 

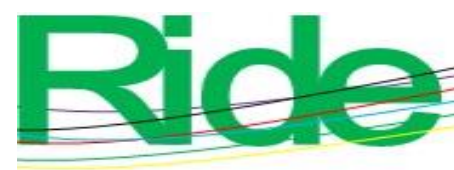

Revista Iberoamericana para la Investigación y el Desarrollo Educativo

ISSN 2007 - 7467

En la actualidad se conoce la correlación positiva que el arte mantiene con la educación, así como que los ambientes agradables o libres de riesgo ayudan a mejorar tanto el aprovechamiento académico de los estudiantes como su desarrollo social y emocional (Catalano, Haggerty, Oesterle, Fleming y Hawkins, 2004; Klem y Connell, 2004).

Por último, Mayo (2018) menciona que la arteterapia mejora la gestión de las emociones, facilita la resolución de conflictos, ayuda en la superación de experiencias dolorosas y disminuye las conductas conflictivas, entre otros beneficios.

\section{Método}

\section{Tipo de estudio}

Se realizó un estudio descriptivo, observacional, de corte cualitativo y no experimental. Todos los sujetos interesados recibieron el tratamiento; no se aplicó muestreo o manejo de grupos experimentales y la aplicación del instrumento fue transversal (Hernández, Fernández y Baptista, 2010).

Se implementó el método de arteterapia de María Fux (2007), adaptado para jóvenes, con 10 sesiones de 120 minutos cada una. En ellas se aplicaron las estrategias y actividades señaladas. Las adaptaciones a los programas se realizaron a partir de la certificación en el método de danzaterapia de Sheykholya (2013) (ver tabla 5). 


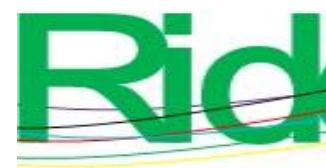

Revista Iberoamericana para la Investigación y el Desarrollo Educativo ISSN 2007 - 7467

Tabla 5. Ejemplo de plan de sesión para talleres de arteterapia

\begin{tabular}{|c|c|c|c|c|}
\hline Actividad & Desarrollo & Música & $\begin{array}{l}\text { Tiem } \\
\text { po }\end{array}$ & $\begin{array}{l}\text { Materi } \\
\text { ales } \\
\text { extra }\end{array}$ \\
\hline Presentación & $\begin{array}{l}\text { El instructor o instructora da la } \\
\text { bienvenida al taller, habla sobre } \\
\text { el objetivo que se quiere lograr } \\
\text { con la intervención, se leen los } \\
\text { lineamientos y se presenta con } \\
\text { los integrantes del grupo. }\end{array}$ & \multirow[t]{2}{*}{$\begin{array}{l}\text { Fresh \& } \\
\text { Chill, } \\
\text { Playlist }\end{array}$} & $\begin{array}{l}10 \\
\min .\end{array}$ & \\
\hline $\begin{array}{l}\text { Presentación } \\
\text { alumnos. } \\
\text { ¿Quién soy } \\
\text { yo?, ¿qué } \\
\text { hago aquí? }\end{array}$ & $\begin{array}{l}\text { En una ronda, los participantes } \\
\text { se presentan: nombre, edad, } \\
\text { profesión. Tendrán la } \\
\text { oportunidad de conocerse y } \\
\text { compartir lo que deseen. } \\
\text { Deberán contestar las preguntas } \\
\text { planteadas: ¿quién soy yo?, ¿qué } \\
\text { hago aquí?, ¿cuáles son mis } \\
\text { expectativas?, ¿cómo me siento } \\
\text { hoy? }\end{array}$ & & $\begin{array}{l}15 \\
\text { min. }\end{array}$ & \\
\hline Caminata & $\begin{array}{l}\text { El participante empezará a } \\
\text { caminar por el espacio, } \\
\text { observando a sus compañeros, } \\
\text { observando el lugar, } \\
\text { identificando todo lo nuevo: } \\
\text { aquellos distractores, aquello } \\
\text { que le agrada. En esta caminata } \\
\text { se podrá interactuar solo con } \\
\text { gestos, saludos, muecas, } \\
\text { evitando mirar al piso, estirando } \\
\text { aquellas partes del cuerpo que } \\
\text { tiene atrofiadas. La respiración } \\
\text { es importante; hacer conciencia } \\
\text { de la respiración. }\end{array}$ & $\begin{array}{l}\text { Gravity } \\
\text { Instrumen } \\
\text { tal, Lance } \\
\text { Allen }\end{array}$ & $\begin{array}{l}5 \\
\min .\end{array}$ & \\
\hline $\begin{array}{l}\text { Caminata } \\
\text { con } \\
\text { calentamient } \\
\text { o }\end{array}$ & $\begin{array}{l}\text { Moviendo el cuerpo, haciendo } \\
\text { énfasis en las partes del cuerpo } \\
\text { que se van señalando, a manera } \\
\text { de calentamiento, llevando el } \\
\text { movimiento de los pies a la } \\
\text { cabeza, pasando por las piernas, } \\
\text { caderas, orzo, brazos, cuello y } \\
\text { las manos. }\end{array}$ & $\begin{array}{l}\text { Nizzagh } \\
\text { Ijbal, } \\
\text { Tinariwen }\end{array}$ & $\begin{array}{l}5 \\
\text { min. }\end{array}$ & \\
\hline
\end{tabular}




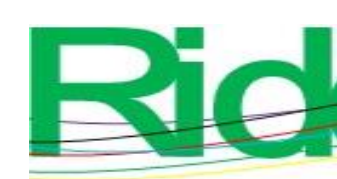

Revista Iberoamericana para la Investigación y el Desarrollo Educativo ISSN 2007 - 7467

\begin{tabular}{|c|c|c|c|c|}
\hline $\begin{array}{l}\text { Círculo de } \\
\text { presentación }\end{array}$ & $\begin{array}{l}\text { Se ponen todos los participantes } \\
\text { de pie y, para romper el hielo, se } \\
\text { mencionan situaciones o } \\
\text { características que cada uno } \\
\text { desea conocer de sus } \\
\text { compañeros; los que coincidan } \\
\text { con esa descripción dan un paso } \\
\text { al centro del círculo y, si gustan, } \\
\text { pueden dar réplica o explicar. }\end{array}$ & $\begin{array}{l}\text { Fresh \& } \\
\text { Chill, } \\
\text { Playlist }\end{array}$ & $\begin{array}{l}15 \\
\min .\end{array}$ & \\
\hline Dibujo libre & $\begin{array}{l}\text { De manera individual se solicita } \\
\text { que elaboren un dibujo. Al } \\
\text { finalizar, se pone el ejemplo de } \\
\text { cómo en parejas interpretarán el } \\
\text { dibujo de acuerdo con sus } \\
\text { características, en donde el autor } \\
\text { del dibujo le prestará la voz a esa } \\
\text { característica: Hola, ¿quién eres? } \\
\text { ¿Para qué sirves? ¿Cómo te } \\
\text { sientes haciendo eso? ¿Qué te } \\
\text { gustaría hacer? }\end{array}$ & & $\begin{array}{l}30 \\
\min .\end{array}$ & $\begin{array}{l}\text { Hojas } \\
\text { blancas } \\
\text { y } \\
\text { lápices } \\
\text { de } \\
\text { colores }\end{array}$ \\
\hline $\begin{array}{l}\text { Soy una } \\
\text { serpiente }\end{array}$ & $\begin{array}{l}\text { Los participantes se colocan en } \\
\text { diferentes espacios en toda el } \\
\text { aula, y siguen la ronda infantil, } \\
\text { pasando por el túnel de piernas } \\
\text { cuando se les invite a formar } \\
\text { parte de la cola de la serpiente. }\end{array}$ & $\begin{array}{l}\text { Soy una } \\
\text { serpiente, } \\
\text { Duo } \\
\text { tiempo de } \\
\text { sol. }\end{array}$ & $\begin{array}{l}5 \\
\min .\end{array}$ & \\
\hline $\begin{array}{l}\text { La escultura } \\
\text { perfecta }\end{array}$ & $\begin{array}{l}\text { Los participantes se colocarán en } \\
\text { parejas, por turnos tomarán un } \\
\text { pincel y lo pasarán por todo el } \\
\text { contorno y facciones de su cara } \\
\text { y cuerpo, resaltando y pensando } \\
\text { en sus habilidades y destrezas, } \\
\text { para crear la escultura perfecta. }\end{array}$ & $\begin{array}{l}\text { The Key } \\
\text { to } \\
\text { Lallybroc } \\
\text { h, Bear } \\
\text { McCreary } \\
\text {. }\end{array}$ & $\begin{array}{l}5 \\
\min .\end{array}$ & \\
\hline Cierre & $\begin{array}{l}\text { Se habla sobre lo vivido en la } \\
\text { sesión, se comparten } \\
\text { experiencias y aprendizajes, lo } \\
\text { que descubrieron con la } \\
\text { elaboración de los dibujos y } \\
\text { cómo se sintieron. Al finalizar, } \\
\text { todos se colocan de pie, inhalan } \\
\text { profundamente y al exhalar } \\
\text { gritan con todas las fuerzas para } \\
\text { descargar la energía creada } \\
\text { durante la sesión. }\end{array}$ & $\begin{array}{l}\text { Fresh \& } \\
\text { Chill, } \\
\text { Playlist }\end{array}$ & $\begin{array}{l}30 \\
\min .\end{array}$ & \\
\hline
\end{tabular}

Fuente: Elaboración propia 


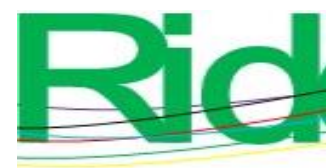

Revista Iberoamericana para la Investigación y el Desarrollo Educativo ISSN 2007-7467

\section{Sujetos}

Se contó con 10 alumnos (tres hombres y siete mujeres) de seis diferentes programas educativos del ITSON que cursaban entre el tercer y séptimo semestre. Su edad oscilaba entre los 19 y 22 años. No existió proceso de selección: se inscribió a alumnos que externaron requerir el taller por causas personales o académicas, especialmente por estrés. Lo anterior se validó con el aval otorgado por el responsable del programa educativo del alumno y su historial de calificaciones y materias dadas de baja durante el último año cursado.

\section{Técnicas e instrumentos}

A través de la técnica de observación participante y mediante un diario de campo, se recabó la información de la intervención: se realizaron narrativas-descripciones del desarrollo de las actividades y el desenvolvimiento de los participantes al final de cada sesión. Como base se utilizó una escala de observación tipo Likert de 20 ítems, a manera de entradasalida o test-postest, revisada por tres expertos de contenido (ver tabla 6). Su aplicación fue previa al taller, durante y al cierre de este. Los análisis estadísticos se realizaron con el paquete SPSS 


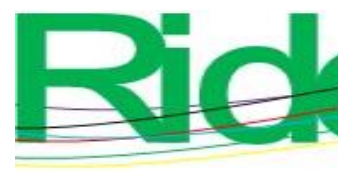

Revista Iberoamericana para la Investigación y el Desarrollo Educativo ISSN 2007 - 7467

Tabla 6. Instrumento de entrada y salida aplicado a universitarios

\begin{tabular}{|c|c|c|c|c|c|}
\hline Criterios a observar en talleres de arteterapia & 离 & 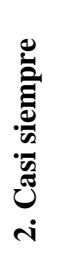 & 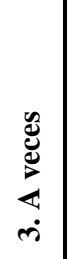 & 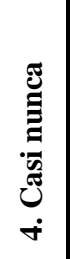 & $\underset{\text { ம் }}{\stackrel{\Xi}{E}}$ \\
\hline 1.Se le facilita comentar sucesos cotidianos de su vida. & & & & & \\
\hline 2.Prefiere actividades individuales que grupales. & & & & & \\
\hline 3.Muestra paciencia en actividades que tienen un tiempo establecido. & & & & & \\
\hline 4.Se percibe que disfruta actividades plásticas. & & & & & \\
\hline 5.Se observa el gusto por actividades con movimiento corporal. & & & & & \\
\hline 6.Podría trabajar con grupos heterogéneos u homogéneos. & & & & & \\
\hline 7.Participar activamente. & & & & & \\
\hline 8.Tiende a ser creativo en actividades corporales o prácticas. & & & & & \\
\hline $\begin{array}{l}\text { 9.Comenta sobre su creación plástica después de trabajar con los } \\
\text { materiales. }\end{array}$ & & & & & \\
\hline $\begin{array}{l}\text { 10.Realiza retroalimentación después de algún ejercicio individual o } \\
\text { grupal. }\end{array}$ & & & & & \\
\hline 11.Muestra interés en el trabajo de equipo. & & & & & \\
\hline 12.Se le facilita realizar actividades motrices-de coordinación. & & & & & \\
\hline 13.Muestra interés por la estimulación musical. & & & & & \\
\hline 14.Tiende a desenvolverse con facilidad en el espacio de trabajo. & & & & & \\
\hline $\begin{array}{l}\text { 15.Da a conocer situaciones vividas después de trabajar con } \\
\text { contenido matérico y el cuerpo. }\end{array}$ & & & & & \\
\hline 16.Proyecta emociones o sentimientos. & & & & & \\
\hline 17.Tiende a verbalizar sobre situaciones incómodas, y da soluciones. & & & & & \\
\hline 18.Muestra empatía con los integrantes del grupo. & & & & & \\
\hline $\begin{array}{l}\text { 19.Muestra hacia quienes integran el grupo a partir de las emociones } \\
\text { surgidas en las dinámicas. }\end{array}$ & & & & & \\
\hline 20.Comentario libre: & & & & & \\
\hline
\end{tabular}

Fuente: Elaboración propia 


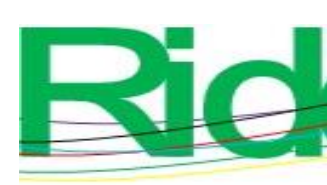
Revista Iberoamericana para la
Investigación y el Desarrollo Educativo
ISSN $2007-7467$

\section{Resultados}

Las actividades que se trabajaron fueron las siguientes: exploración libre, movimiento por segmentos corporales, en el espacio parcial y total con apoyo de música de diferentes géneros y estilos. Se trabajó de manera individual, en parejas, en equipos y grupal la imitación de movimientos, coreografías empleando los diferentes niveles y calidades del movimiento; se promovió la creatividad corporal y plástica (ver figura 2), así como el movimiento original a través del juego y role-playing; se hizo uso de objetos para motivar el gusto por su empleo y materiales que incitaran a plasmar lo vivenciado.

Figura 2. Actividades de trabajo corporal plástico

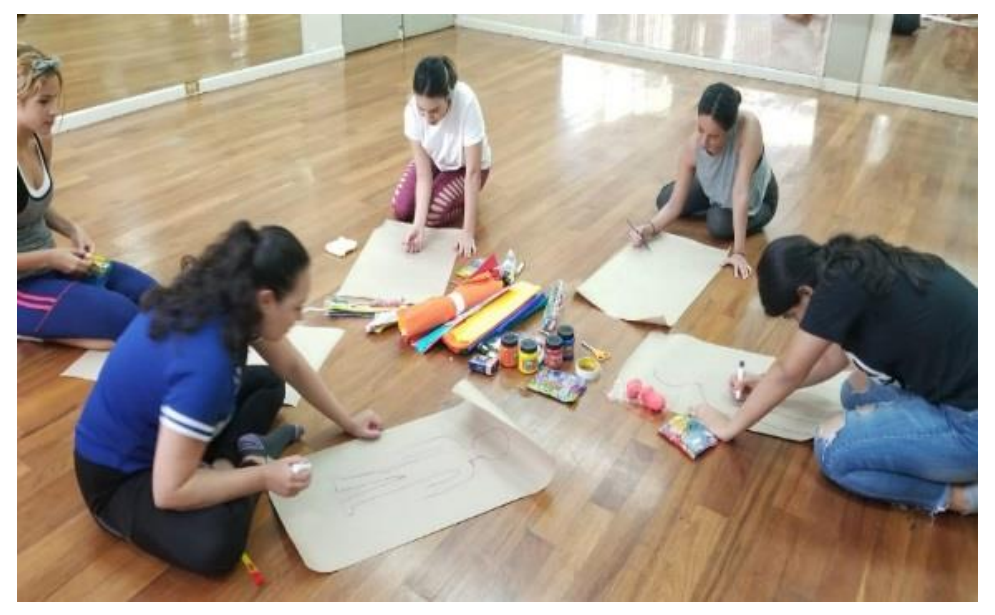

Fuente: Elaboración propia

Entre los resultados de las intervenciones se pudieron conocer los temas de interés y las preocupaciones con las que en esos momentos estaban lidiando. Entre ellos se encuentran: el amor vs. la decepción; la alegría vs. la tristeza; la motivación vs. lo desalentador; el enojo vs. la felicidad; la actitud vs. la depresión, y la tranquilidad vs. la ansiedad, entre otras. Y entre las cosas que suelen preocuparles y ocuparles gran parte de su tiempo se encuentran: el no rendir en el gimnasio, la muerte de alguna persona, la falta de amigos, la no aceptación social, el no tener dinero, la preferencia sexual, la falta de comunicación con los padres, no contar con ellos o la falta de alguno de los dos, el trabajar y estudiar, la baja autoestima, la falta de habilidades comunicativas, la relación de pareja, el estudiar una carrera que no les agrada y la falta de afecto, entre otras que por el solo hecho de no ser atendidas han sido motivo de reprobación, deserción, condicionamientos académicos que llevan al fracaso escolar. 


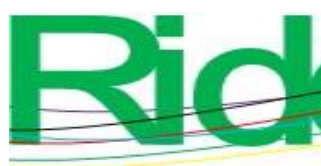

Tabla 3. Resultados de frecuencia y alfa de la aplicación de entrada o inicio (observaciones a manera de test o diagnóstico)

\begin{tabular}{|l|l|l|l|l|l|l|l|l|l|}
\hline Indicadores & S & CS & A & CN & N & Med & DE & Mín. & Máx. \\
\hline $\begin{array}{l}\text { 1) Se fecilita comentar } \\
\text { sucesos cotidianos de su vida. }\end{array}$ & 4 & 2 & 2 & 2 & 0 & 3.80 & 1.23 & 2 & 5 \\
\hline $\begin{array}{l}\text { 2) Prefiere actividades } \\
\text { individuales que grupales. }\end{array}$ & 10 & 0 & 0 & 0 & 0 & 1 & 0 & 1 & 1 \\
\hline $\begin{array}{l}\text { 3) Muestra paciencia en } \\
\text { actividades que tienen un tiempo } \\
\text { establecido. }\end{array}$ & 7 & 1 & 1 & 1 & 1 & 4.30 & 1.34 & 1 & 5 \\
\hline $\begin{array}{l}\text { 4) Se percibe que disfruta } \\
\text { actividades plásticas. }\end{array}$ & 6 & 3 & 0 & 0 & 1 & 4.30 & 1.25 & 1 & 5 \\
\hline $\begin{array}{l}\text { 5) Se observa el gusto por } \\
\text { actividades con movimiento } \\
\text { corporal. }\end{array}$ & 1 & 0 & 0 & 0 & 9 & 1.40 & 1.25 & 1 & 5 \\
\hline $\begin{array}{l}\text { 6) Podría trabajar con grupos } \\
\text { heterogéneos u homogéneos. }\end{array}$ & 0 & 1 & 0 & 0 & 9 & 1.30 & 0.95 & 1 & 4 \\
\hline 7) Participar activamente. & 4 & 4 & 1 & 0 & 1 & 4 & 1.25 & 1 & 5 \\
\hline $\begin{array}{l}\text { 8) Tiende a ser creativo en } \\
\text { actividades corporales o prácticas. }\end{array}$ & 4 & 2 & 0 & 0 & 4 & 3.20 & 1.93 & 1 & 5 \\
\hline $\begin{array}{l}\text { 9) Comenta sobre su creación } \\
\text { plástica después de trabajar con los } \\
\text { materiales. }\end{array}$ & 4 & 4 & 2 & 0 & 0 & 4.20 & 0.79 & 3 & 5 \\
\hline $\begin{array}{l}\text { 10) Realiza retroalimentación } \\
\text { después de algún ejercicio } \\
\text { individual o grupal. }\end{array}$ & 2 & 4 & 2 & 0 & 2 & 3.40 & 1.43 & 1 & 5 \\
\hline $\begin{array}{l}\text { 11) Muestra interés en el trabajo } \\
\text { en equipo. }\end{array}$ & 0 & 1 & 0 & 0 & 9 & 1.30 & 0.95 & 1 & 4 \\
\hline $\begin{array}{l}\text { 12) Se le facilita realizar } \\
\text { actividades motrices de } \\
\text { coordinación. }\end{array}$ & 0 & 0 & 0 & 1 & 9 & 1.40 & 1.26 & 1 & 5 \\
\hline $\begin{array}{l}\text { 13) Muestra interés por la } \\
\text { estimulación musical. }\end{array}$ & 0 & 0 & 0 & 0 & 10 & 1 & 0 & 1 & 1 \\
\hline
\end{tabular}




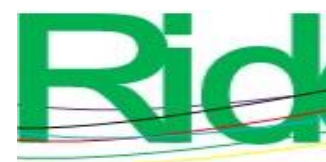

Revista Iberoamericana para la Investigación y el Desarrollo Educativo ISSN 2007 - 7467

\begin{tabular}{|l|l|l|l|l|l|l|l|l|l|}
\hline $\begin{array}{l}\text { 14) Tiende a desenvolverse con } \\
\text { facilidad en el espacio de trabajo. }\end{array}$ & 2 & 1 & 1 & 0 & 6 & 2.30 & 1.77 & 1 & 5 \\
\hline $\begin{array}{l}\text { 15) Da a conocer situaciones } \\
\text { vividas después de trabajar con } \\
\text { contenido matérico y el cuerpo. }\end{array}$ & 5 & 3 & 2 & 0 & 0 & 4.30 & 0.82 & 3 & 5 \\
\hline $\begin{array}{l}\text { 16) Proyecta emociones o } \\
\text { sentimientos. }\end{array}$ & 7 & 3 & 0 & 0 & 0 & 4.70 & 0.48 & 4 & 5 \\
\hline $\begin{array}{l}\text { 17) Tiende a verbalizar sobre } \\
\text { situaciones incómodas, y da }\end{array}$ & 4 & 4 & 2 & 0 & 0 & 4.20 & 0.79 & 3 & 5 \\
soluciones. & & & & & & & & & \\
\hline $\begin{array}{l}\text { 18) Muestra empatía con los } \\
\text { integrantes del grupo. }\end{array}$ & 1 & 1 & 0 & 1 & 4.30 & 1.34 & 1 & 5 \\
\hline $\begin{array}{l}\text { 19) Muestra empatía hacia } \\
\text { quienes integran el grupo a partir de } \\
\text { las emociones surgidas en las } \\
\text { dinámicas. }\end{array}$ & & 1 & 1 & 0 & 0 & 4.70 & 0.67 & 3 & 5 \\
\hline
\end{tabular}

Fuente: Elaboración propia 

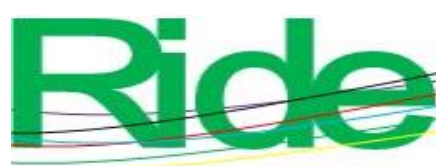

Revista Iberoamericana para la Investigación y el Desarrollo Educativo ISSN 2007 - 7467

Tabla 4. Resultados de frecuencia y alfa de aplicación de salida (postest u observaciones finales)

\begin{tabular}{|c|c|c|c|c|c|c|c|c|c|}
\hline Indicadores & $\mathbf{S}$ & $\mathrm{CS}$ & $\mathbf{A}$ & $\mathbf{C N}$ & $\mathbf{N}$ & Med & DE & Mín. & Máx. \\
\hline $\begin{array}{l}\text { 1) } \mathrm{Se} \text { le facilita comentar } \\
\text { sucesos cotidianos de su vida. }\end{array}$ & 7 & 2 & 1 & 0 & 0 & 4.60 & 0.70 & 3 & 5 \\
\hline $\begin{array}{l}\text { 2) Prefiere actividades } \\
\text { individuales que grupales. }\end{array}$ & 0 & 0 & 3 & 2 & 5 & 1.80 & 0.92 & 1 & 3 \\
\hline $\begin{array}{l}\text { 3) Muestra paciencia en } \\
\text { actividades que tienen un tiempo } \\
\text { establecido. }\end{array}$ & 8 & 2 & 0 & 0 & 0 & 4.80 & 0.42 & 4 & 5 \\
\hline $\begin{array}{l}\text { 4) } \mathrm{Se} \text { percibe que disfruta } \\
\text { actividades plásticas. }\end{array}$ & 8 & 2 & 0 & 0 & 0 & 4.80 & 0.42 & 4 & 5 \\
\hline $\begin{array}{l}\text { 5) } \text { Se observa } \text { el gusto por } \\
\text { actividades } \\
\text { con con }\end{array}$ & 5 & 0 & 5 & 0 & 0 & 4 & 1.05 & 35 & 5 \\
\hline $\begin{array}{l}\text { 6) Podría trabajar con grupos } \\
\text { heterogéneos u homogéneos. }\end{array}$ & 10 & 0 & 0 & 0 & 0 & 5 & 0 & 5 & 5 \\
\hline 7) $\quad$ Participar activamente. & 9 & 1 & 0 & 0 & 0 & 4.90 & 0.32 & 4 & 5 \\
\hline $\begin{array}{l}\text { 8) Tiende a ser creativo en } \\
\text { actividades corporales y/o prácticas. }\end{array}$ & 8 & 2 & 0 & 0 & 0 & 4.80 & 0.42 & 4 & 5 \\
\hline $\begin{array}{l}\text { 9) Comenta sobre su creación } \\
\text { plástica después de trabajar con los } \\
\text { materiales. }\end{array}$ & 9 & 1 & 0 & 0 & 0 & 4.90 & 0.32 & 4 & 5 \\
\hline $\begin{array}{l}\text { 10) Realiza retroalimentación } \\
\text { después de algún individual o } \\
\text { grupal. }\end{array}$ & 7 & 2 & 0 & 1 & 0 & 4.50 & 0.97 & 2 & 5 \\
\hline $\begin{array}{l}\text { 11) Muestra interés en el trabajo } \\
\text { de equipo. }\end{array}$ & 8 & 2 & 0 & 0 & 0 & 4.80 & 0.42 & 4 & 5 \\
\hline 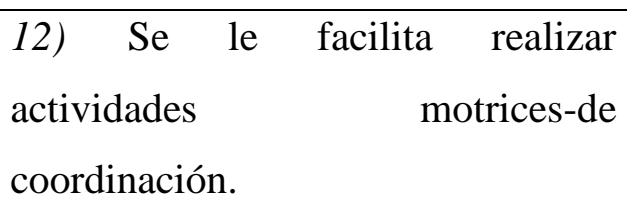 & 7 & 3 & 0 & 0 & 0 & 4.70 & 0.48 & 4 & 5 \\
\hline
\end{tabular}




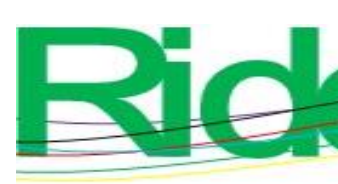

Revista Iberoamericana para la Investigación y el Desarrollo Educativo ISSN $2007-7467$

Figura 1. Actividades para el desarrollo de la creatividad

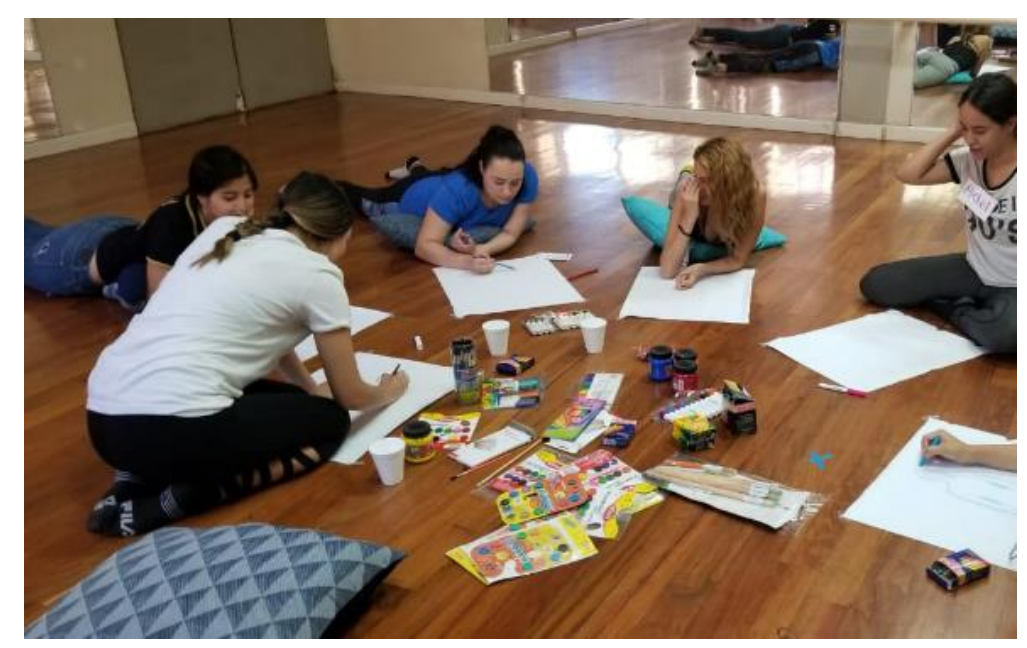

Fuente: Elaboración propia

Las preguntas 9 y 10 también tuvieron un avance regular de casi siempre a siempre en la mayoría de los chicos. El ítem 11, sobre el trabajo en equipo, marcó un aumento particularmente significativo: fue de casi nunca y nunca a casi siempre y siempre en $90 \%$ de los participantes. Algo análogo se presentó en el ítem 12, de motricidad y coordinación, donde al final $80 \%$ respondió que siempre y $20 \%$ casi siempre, es decir, se revirtió el hecho de que al principio no les agradaba o no se les facilitaba. Lo mismo para el ítem 13, de estimulación musical: al inicio era evidente que no les agradaba a los alumnos, tal vez correlacionado con la motricidad, pero al final $70 \%$ mostró agrado por las actividades con música y $30 \%$ al menos algunas veces.

En la pregunta 14, a $60 \%$ de los jóvenes se les dificultaba en un inicio trabajar en el espacio dispuesto; al final, en la misma situación, se observó cómo ya no tuvieron ese problema. Y en el ítem 15, del trabajo con materiales y contar situaciones vividas, al principio solo la mitad lo podía hacer con gusto, pero al final ya casi siempre o siempre podían compartir experiencias la totalidad de los involucrados. Lo que sí es que en el ítem 16, relacionado a la expresión de emociones, esto subió muy poco, aunque los porcentajes ya se localizaban del lado positivo de la escala. En el ítem 17, el cual gira en torno a verbalizar situaciones incómodas que les pasan y dar soluciones a ello, subió favorablemente el porcentaje: de $40 \%$ a $70 \%$. Igualmente, la empatía mostrada a sus compañeros se elevó de $70 \%$ a $100 \%$ en el ítem 18 . Y en la pregunta 19 , ya $100 \%$ de los alumnos podía mostrarse con sus emociones de forma natural en el grupo (ver tablas 3 y 4 ). 

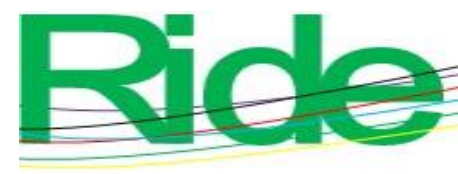

Revista Iberoamericana para la Investigación y el Desarrollo Educativo ISSN $2007-7467$

Finalmente, en el ítem abierto número 20, mayormente cualitativo, que era hacer algún comentario libre, anotar algunas últimas observaciones, se tomó nota durante la implementación de las sesiones que los participantes estuvieron externando su sentir, sus emociones se reflejaron en cada actividad o estrategia aplicada, se contó con disposición de los muchachos y aunque a veces se detenían por tener dudas de lo que se esperaba de ellos, al disiparlas se integraban de nuevo para continuar los ejercicios. Se destacan algunas a continuación:

Sujeto 3, del grupo 1 (femenino, 20 años): Comenta que desde pequeña está muy familiarizada con el baile porque participó en distintos géneros de danza. Le gusta colorear y pintar, le recuerda mucho a su niñez (ver figura 3). Comenta que, en su vida diaria, cuando piensa en los ejercicios que hace en arteterapia, le da felicidad (sesión 5).

Sujeto 5, del grupo 1 (masculino, 19 años): Nos comentó que su más grande logro en el taller fue sentir un alivio del dolor de la muerte de su abuela, ya que nunca había dicho lo que sentía y, al momento de platicarlo, se sintió bien, sin algún peso encima que lo perturbaba. Y otra de las cosas fue que decidió estudiar sin miedo, solo echarle ganas por sus papás (sesión 8).

Sujeto 2, del grupo 2 (femenino, 22 años): Con la actividad de ¿Quién soy? habló un poco más y compartió lo que ella piensa y quiere para sí misma. En la actividad de los sentimientos comentó que para cada uno tenía que recordar un momento en que lo vivió para identificarlo, pero nos dice que los sentimientos negativos le costaron un poco más de trabajo porque les tiene pánico y entra como en crisis. Es por eso que evita hablar mucho, solo habla con sus amigas porque la hacen reír y olvidar lo malo (sesión 2). 

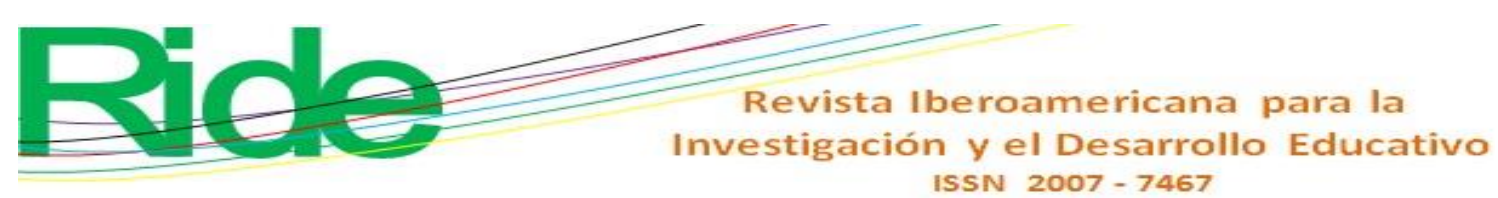

Figura 3. Actividades para plasmar emociones y evocar recuerdos

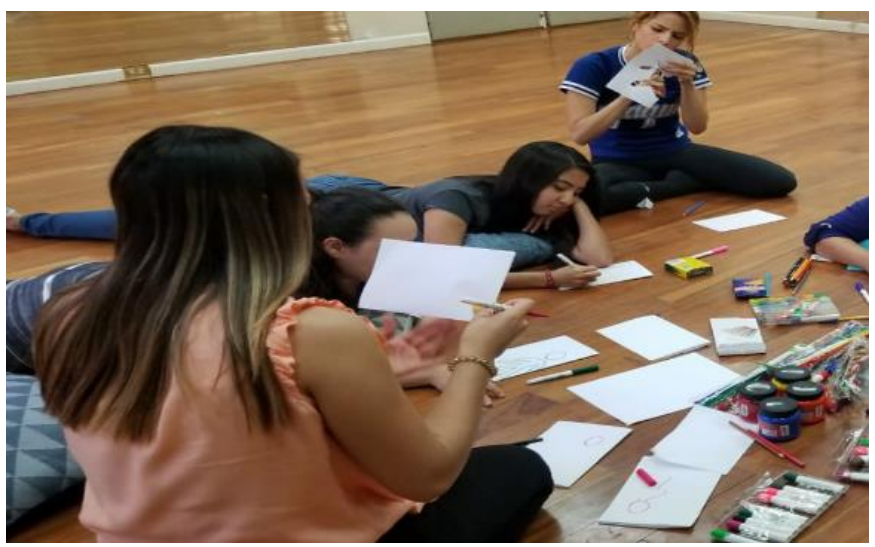

Fuente: Elaboración propia

El programa arteterapéutico aplicado ha sido útil en muchos sentidos. De forma grupal, ya que se creó un sentido de pertenencia al expresar las vivencias, sensaciones y emociones, lo que produjo un vínculo al experimentar sentimientos comunes entre sí, ya que pasan por situaciones similares, y esto, a su vez, da lugar a la empatía, al respeto, a la tolerancia y al sentido de solidaridad. También se generó un ambiente de confianza, donde hay libertad de actuar, de hacer, de decir; donde no se juzga, se rechaza o discrimina, más bien se incluye, integra, gracias a lo cual se conforma un círculo de apoyo y hermandad. Además, el hecho de que se haya realizado por una universitaria para universitarios ayudó en la motivación de ver a uno de sus iguales apoyando causas vividas.

En lo personal se desarrolló la expresión en diversas maneras, ya sea oral, plástica, con movimiento, la expresión corporal, con las letras, sonidos e incluso en la proyección en la otra persona, es decir, aunque no se diga con palabras, el hecho de que quien sí lo realice sirve también como forma de liberar lo latente, todo lo cual permitió avances en la expresión hablada y corporal, de habilidades comunicativas y sociales, floreció la creatividad en todos los campos de acción y se trabajó con el conocimiento de sí mismo, su problemática, así como el darse cuenta de la posible solución a su situación.

Con respecto a lo cuantitativo, aunque todavía no se determina la correlación entre la disminución del estrés y la mejora del rendimiento académico, se puede señalar, a partir de la información recabada con los responsables de bajas de los programas educativos de los que provienen los beneficiados, que en el semestre posterior a la aplicación del taller de arteterapia ninguno de los muchachos dio de baja sus materias, de forma total o parcial, y hubo un porcentaje de aprobación de $100 \%$. Se ha solicitado, adicionalmente, las calificaciones y promedio del último año cursado antes del taller y de los siguientes dos 


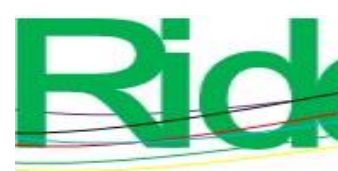

Revista Iberoamericana para la
Investigación y el Desarrollo Educativo
ISSN $2007-7467$

semestres; sin embargo, eso sigue en proceso, dado que serán los mismos alumnos quienes tendrán que proporcionarlas y autorizar su uso con fines de investigación. Esto ha llevado al grupo de trabajo a establecer algunas políticas para la selección de inscritos en los talleres de arteterapia: solicitar, en primer lugar, información de resultados académicos previos al taller; y en segundo, una carta donde se comprometan a otorgar su kárdex posterior anual, y así contar con la información para darles seguimiento.

\section{Discusión}

Lo anterior coincide con lo encontrado por Mundet, Beltrán y Moreno (2015), quienes señalan que las actividades artísticas son una herramienta óptima de acción socioeducativa con jóvenes, por ello es importante seguir implementando y desarrollando holísticamente proyectos educativos centrados en la actividad artística. Y también con lo encontrado por Aguilera, Molina y Méndez (2019), que lograron identificar un estado físico, mental y emocional desgastante en sus siete participantes universitarias, lo que generaba en ellas una serie de síntomas somáticos y emocionales, a causa de la sobrecarga de responsabilidades laborales y académicas, y, a su vez, se logró evaluar y comprobar que la arteterapia sí es efectiva para la reducción del estrés; señalan, sin embargo, que para tener un efecto prolongado es preciso integrarlo a la rutina y crear hábitos de autocuidado

En esa misma línea, según López, Feíto y Rodríguez (2016), con la aplicación de estos programas los alumnos involucrados han señalado que tienen mayor apertura para expresar sus emociones, que han logrado moderar su carácter explosivo, al igual que ser más sociables.

Como señala María Fux (citada en Pereira, 18 de agosto de 2016), autora del método, no se trata de curar a la gente, es darles la oportunidad de cambiar, es otra forma de potenciar sus habilidades. Finalmente, esta investigación también coincide con la realizada por Champa (2018), quien señala que hay algo más que la arteterapia permite, ya que, al facilitar reconocer y resolver conflictos, también ayuda a la persona a detectar situaciones de riesgo social, y por tanto, le permite actuar en el marco de la intervención primaria y prevenir nuevas dificultades sociales.

Sin embargo, este estudio debe replicarse con un mayor número de estudiantes, que impacte en una población estudiantil más grande, y seguir certificando a instructores de la licenciatura en Gestión y Desarrollo de las Artes u otros programas con alumnos de 


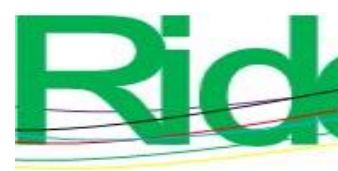

Revista Iberoamericana para la
Investigación y el Desarrollo Educativo
ISSN $2007-7467$

formación afín a la educación artística o la psicología, ya que así se podrá contar con una mayor oferta de talleres, horarios y sedes de aplicación. También se deberá conseguir recurso económico para becar a las talleristas y comprar mayor cantidad de materiales. Eso permitirá convertir a este estudio en longitudinal y correlacional, con nueva información para ajustar el programa de intervención y, por qué no, también descubrir en qué medida la participación de los jóvenes universitarios mejoran su rendimiento académico con estos talleres de arteterapia.

\section{Conclusiones}

La participación libre, activa y positiva favoreció los resultados cualitativos observados por sesión. Los comentarios realizados por los alumnos señalaron la disminución del estrés y atención a temáticas o sentimientos que ellos temían externar. Se logró un ambiente relajado, productivo y positivo, donde, señalaron, lograron sentirse acompañados y con la confianza de platicar sus emociones.

Ambos métodos empleados buscan el desarrollo creativo pleno de la persona a través del autoconocimiento, aprendiendo de sus posibilidades y aceptando sus limitaciones. Como se ha visto aquí, lo anterior se puede trasladar a lo académico. En estos talleres se buscó disminuir la ansiedad que provoca realizar actividades propias de la vida universitaria y sus distintos estresores. Cabe subrayar que todos los alumnos participantes señalaron haberse sentido acompañados y más seguros de poder continuar con sus cursos inscritos, además de sentirse capaces de afrontar sus problemáticas personales, las cuales, sumadas a las académicas o profesionales, eran las principales causas de dar de baja sus materias, o bien fracasar en ellas, lo que, según sus comentarios de salida, ya pudieron sobrellevar con mejor actitud y seguridad. Asimismo, señalaron que están haciendo uso con mayor éxito de sus habilidades personales y académicas.

Se recomienda realizar más habilitación de alumnas de la carrera de Gestión de las Artes, que se certifiquen en arteterapia para lograr tener más oportunidades de acceso a los talleres para alumnos que sientan requerirlos, así como hacer contacto con los tutores de las carreras para que recomienden o canalicen alumnos con problemas académicos o emocionales, ya sea de forma preventiva o remedial, aunado a mejorar la comunicación con los coordinadores de las carreras o programas educativos para que estén informados de los periodos de aplicación de los talleres y, a través de los tutores o el programa institucional de 


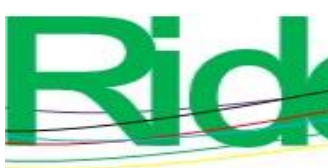

Revista Iberoamericana para la
Investigación y el Desarrollo Educativo
ISSN $2007-7467$

tutorías o seguimiento académico, se recomiende a alumnos candidatos a ser beneficiarios de los talleres.

\section{Referencias}

Aguilera, A. Molina, J. y Méndez, K. (2019). Efectividad del arteterapia para la reducción del estrés: El caso de las estudiantes de 5to año de Medicina de FAREM-Estelí, que realizaron prácticas en el Hospital Escuela San Juan de Dios, periodo octubre 2018 abril 2019. Recuperado del repositorio Unan-Managua en http://repositorio.unan.edu.ni/11342/.

Arrieta, K., Díaz, S. y González, F. (2014). Síntomas de depresión y ansiedad en jóvenes universitarios. Prevalencia y factores asociados. Clínica de Medicina de Familia, 7(1), 14-22. Recuperado de http://scielo.isciii.es/scielo.php?script=sci_arttext\&pid=S1699695X2014000100003.

Barraza A. (2011). La gestión del estrés académico por parte del orientador educativo. El papel de las estrategias de afrontamiento. Visión Educativa IUNAES, 5(11), 36-44. Recuperado de_https://dialnet.unirioja.es/servlet/articulo?codigo=4034497.

Casaliglla, K. (2019). El uso de arteterapia para incrementar la motivación intrínseca y disminuir la deserción escolar. (tesis de licenciatura). Universidad de San Francisco de Quito, Quito. $\quad$ Recuperado de http://repositorio.usfq.edu.ec/bitstream/23000/8205/1/142598.pdf.

Catalano, R. F., Haggerty, K. P, Oesterle, S., Fleming, C. B. and Hawkins, J. D. (2004). The Importance of Bonding to School for Healthy Development: Findings from the Social Development Research Group. Journal of School Health, 74(7), 252-261. Retrieved from

http://citeseerx.ist.psu.edu/viewdoc/download?doi=10.1.1.464.4284\&rep=rep1\&typ e $=$ pdf.

Champa E. (2018). Arteterapia y sus aplicaciones en problemáticas socioemocionales.

$\begin{array}{llll}\text { Temática } & \text { Psicológica, } & \text { 14(1), } & \text { 27-40. }\end{array}$ http://revistas.unife.edu.pe/index.php/tematicapsicologica/article/view/1808/2096.

Dalley, T. (1987). El Arte como terapia. Barcelona, España: Herder.

Fux, M. (2007). Ser danzaterapeuta hoy. Argentina: Lumen. 

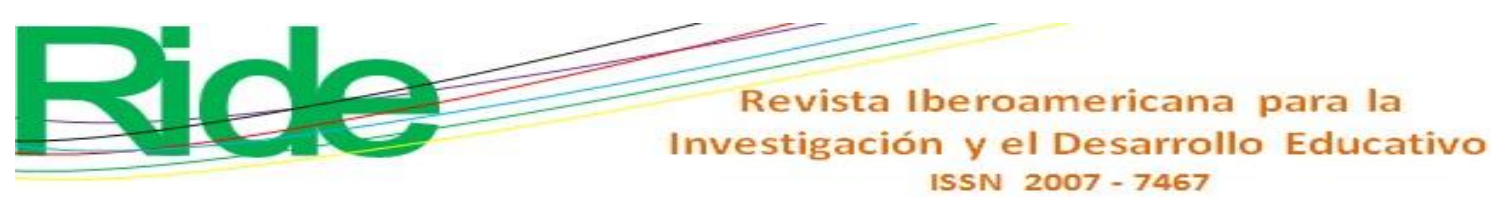

Gardner, H. (2016). Inteligencias múltiples. La teoría en la práctica. México: Paidós.

Gutiérrez, J., Montoya, L., Toro, B., Briñon, M., Rosas, E. y Salazar, L. (2010). Depresión en estudiantes universitarios y su asociación con el estrés académico. CES Medicina, 24(1), 7-17. Recuperado de http://revistas.ces.edu.co/index.php/medicina/article/view/1011/735.

Hernández, R., Fernández, C. y Baptista, L. (2010). Metodología de la investigación (5. ${ }^{a}$ ed.). México: McGraw-Hill.

Klem, A. M. and Connell, J. P. (2004). Relationships Matter: Linking Teacher Support to Student Engagement and Achievement. Journal of School Health, 74(7), 262-273. Retrieved from https://www.semanticscholar.org/paper/Relationships-matter\%3Alinking-teacher-support-to-Klem Connell/e2e7b810eedf1ef2fb510f36588d61640f1879ae.

López, J., Feíto, F. y Rodríguez, T. (2016). Expresión de emociones, resolución de conflictos y autoconocimiento mediante el uso de técnicas de arteterapia. Artículo presentado en el Séptimo Encuentro Nacional de Tutoría. Guanajuato, del 22 al 25 de noviembre de 2016. Recuperado de https://oa.ugto.mx/expresion-de-emociones-resolucion-deconflictos-y-autoconocimiento-mediante-el-uso-de-tecnicas-de-arteterapia.html.

Mayo, E. (2018). Vulnerabilidad, ruptura social y arteterapia. Arteterapia. Papeles de arteterapia y educación para inclusión social, 13, 103-117. Recuperado de https://search.proquest.com/openview/08e83f6f142edef6d68bcb73c92726e0/1?pqorigsite $=$ gscholar $\& \mathrm{cbl}=54821$

Mundet, B. A., Beltrán H. A. M. y Moreno G. A (2015). Arte como herramienta social y educativa. Revista Complutense de Educación, 26(2), 315-329. Recuperado de http://dx.doi.org/10.5209/rev_RCED.2015.v26.n2.43060

Páez, M. y Castaño, J. (2015). Inteligencia emocional y rendimiento académico en estudiantes universitarios. Psicología desde el Caribe, 32(2), 268-285. Recuperado de

http://rcientificas.uninorte.edu.co/index.php/psicologia/article/viewFile/5798/6984.

Pereira, J. (18 de agosto de 2016). María Fux - La vida es movimiento a través de la danzaterapia. QMayor Magazine. Recuperado de https://www.qmayor.com/cultura/maria-fux-la-vida-es-movimiento/.

Sheykholya, A. (2013). El corazón danzado: la psicoterapia de la danza. Estados Unidos: Palibrio. 


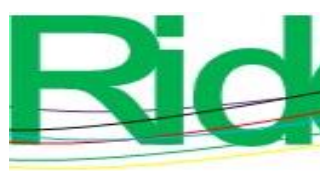

Revista Iberoamericana para la Investigación y el Desarrollo Educativo ISSN $2007-7467$

Toribio, C. y Franco S. (2016). Estrés académico. El enemigo silencioso del estudiante. Revista Salud y Administración, 3(7), 11-18. Recuperado de http://www.unsis.edu.mx/revista/doc/vol3num7/A2_Estres_acad.pdf

\begin{tabular}{|c|c|}
\hline Rol de Contribución & Autor (es) \\
\hline Conceptualización & Grace Rojas-principal \\
\hline Metodología & Grace Rojas-principal \\
\hline Software & Grace Rojas-principal y Luz Galván-Igual \\
\hline Validación & Grace Rojas-principal \\
\hline Análisis Formal & Grace Rojas-principal y Luz Galván-Igual \\
\hline Investigación & Grace Rojas-principal y Luz Galván-Igual \\
\hline Recursos & Grace Rojas-principal y Luz Galván-Igual \\
\hline Curación de datos & Grace Rojas-principal y Luz Galván-Igual \\
\hline $\begin{array}{l}\text { Escritura - Preparación del } \\
\text { borrador original }\end{array}$ & Grace Rojas-principal \\
\hline $\begin{array}{l}\text { Escritura - Revisión y } \\
\text { edición }\end{array}$ & Grace Rojas-principal \\
\hline Visualización & Grace Rojas-principal \\
\hline Supervisión & Grace Rojas-principal \\
\hline $\begin{array}{l}\text { Administración de } \\
\text { Proyectos }\end{array}$ & Grace Rojas-principal y Luz Galván-Igual \\
\hline Adquisición de fondos & Grace Rojas-principal \\
\hline
\end{tabular}

